\title{
Counseling: Establishing a Culture of Forgiveness
}

GEORGE F. NUSSBAUM, PHD, RN, CNOR

Editor's note: This article is reprinted from SSM 2002;8(5):41-46, with permission from AORN, Inc, Denver, CO.

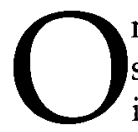

ne responsibility that supervisors dread the most is counseling employees for poor per-

formance or behavior issues. This sort of counseling often results in negative feelings between employees and supervisors. Conflicts with and among employees represent one of the largest reducible costs in organizations, and one of the least recognized. ${ }^{1}$ Approximately $65 \%$ of performance problems are a result of damaged relationships between employees or between employees and supervisors. Performance problems are not just deficits in employee skills or motivation. ' Workplace conflicts from any source, including cultural differences and communication errors, are expensive both in money and wasted time.

\section{Why Not Counsel?}

Marginal employees often can sense the reluctance of supervisors to counsel them and sometimes perform just well enough to avoid a counseling session. Supervisors often fail to bring these individuals behind closed doors because they fear several potential consequences. They are afraid the employee will become angry or react violently. They may be afraid the employee will resign. In many instances, the question becomes whether it would be better to have a marginal employee or none at all. Supervisors often fear counseling will be ineffective. They are concerned the employee will cause chaos among other team members. Supervisors worry the employee will not like them anymore. Will the employee agree with the counseling, yet sabotage the organization in other ways (eg, taking frequent sick days, failing to document legitimate patient charges used during procedures)? Another fear is the employee may point out the supervisor's leadership failures and leave him or her more vulnerable. Perhaps the most pressing concern is that the employee will point out inconsistencies and the unfairness of selectively counseling them while others seem to be worse or guiltier than him or her. The employee may be a long-time staff member whom supervisor after supervisor has been unable to control or fire.

\section{The Cost of Not Counseling}

Good relationships between staff members are important, and conflict can add stress to an already complex environment. Conflicts in organizations represent lost revenue in the form of time wasted worrying, gathering facts, writing counseling statements, conducting counseling, and managing the aftermath. During the course of the conflict, supervisors often make bad decisions, agreeing to compromises that

\section{ABSTRACT}

COUNSELING "PROBLEM EMPLOYEES" can be a painful experience for everyone involved.

THE COUNSELING PROCESS often fails because forgiveness is not a part of organizational culture in the United States.

THIS AUTHOR STRESSES THE NEED for a forgiveness plan that will enable employees to recommit to their jobs. AORN J 86 (September 2007) 415-422. (C AORN, Inc, 2007. 
are intended to rectify the situation but instead exacerbate the problem. Supervisors often make these compromises as a result of their fears. Poor decisions often result in compromises that negatively affect other employees, and this inevitably creates more difficulties. Supervisors who repeatedly make bad decisions and demonstrate a lack of leadership ability frequently lose the respect and trust of staff members. This leads to gradual loss of employees who seek less stressful environments with solid leadership. Senior leaders in an organization may attempt to resolve supervisor-employee problems by unnecessary restructuring, intending to put some space between the conflicting parties. This is an expensive process that ultimately can yield minimal results and greater organizational confusion. While restructuring for the sake of organizational efficiency is valid, it is not valid simply to accommodate poor performance.

Another cost of conflict is that angry and frustrated employees are more likely to sabotage the organization through deceit, abuse of leave and sick benefits, theft, carelessness, and damage to expensive equipment. Continued unresolved conflict within a department results in morale and motivation issues, time lost to gossip, backbiting, backstabbing, and irritation among employees. Employees who are subject to stressful conditions will experience more stress-related symptoms and illnesses. ${ }^{1}$

\section{The Difficulties of Counseling}

Forgiveness in organizations is not customary in the United States. Poor performance or behavior issues normally result in formal counseling sessions, which may place the employee in a no-win situation-they believe there is no hope for future promotions or salary increases. It is for this reason that, unless forgiveness is involved or they are handled correctly, counseling sessions rarely are productive and often are frustrating for all parties involved.

Part of the problem is an incorrect perception on the part of supervisors-they often say that they "have a problem employee." This implies that the problem belongs to the supervisor and that correcting the difficulty is his or her responsibility. Assuming the supervisor can gather sufficient facts, document them well, and confront the employee, the employee either will correct the behavior, resign, or choose not to correct the behavior and be fired. In any case, the supervisor no longer will have the problem.

The fact is, the supervisor never had the problem-he or she only perceived it as such. The reality is the supervisor has an employee who has a problem. Viewed from this perspective, the responsibility of the supervisor is to bring the issue to the surface and allow the employee the opportunity to resolve any concerns. For clarification, these sorts of problems do not include those of a criminal nature, such as illegal drug use, malpractice, or other potential felonies. Instead, these issues include unkind behaviors toward other employees, time and attendance concerns, laziness, failure to complete standard departmental responsibilities, and other behavioral issues.

\section{What Is Counseling?}

If done correctly, counseling should be an exchange of opinions with the intent to reach a decision and form a deliberate plan to resolve problems. When true forgiveness and restoration of harmony is possible, confrontation can be avoided. Supervisors must be willing to 
allow employees to admit their mistakes and to discuss and commit to making required changes. In exchange, the supervisor must work with the employee to maintain their working relationship and to eliminate the problem and all associated documentation completely if the employee complies.

\section{Feeling Threatened}

Confronted in a counseling session, many employees will feel severely threatened. Counseling sessions frequently are the last event at the end of the week and begin with social pleasantries, followed by the supervisor announcing the transgression or transgressions. These situations often become selffulfilling prophecies. In self-defense, the employee becomes angry and defensive. To minimize the damage, he or she begins to deny the magnitude of the issue and points out that he or she is not the only one who has the problem. The employee may believe he or she has been singled out for punishment, that it really is the system's fault, or any number of excuses.

Employees often are skillful enough to pull supervisors into an argument by asking harsh questions or by suggesting weaknesses in the supervisor's ability to lead a department. When this happens, any potential benefit of the counseling is lost. The argument that follows can lead to a break in the working relationship between the two parties. In the worst cases, it may lead to an on-the-spot resignation or termination. At best, the relationship becomes strained and the employee with the problem now has an additional burden to overcome. This instantly diminishes the employee's motivation and is counterproductive to the supervisor's original intent.

\section{Why Do Counseling Sessions Rarely Go Well?}

Counseling sessions often fail to achieve the intended purpose for multiple reasons. The first usually is a lack of skill on the part of the supervisor. Confrontation is not a pleasant activity, so most people avoid it. When a supervisor finally decides to call in an employee, he or she buries the real issue under other matters. In the end, the supervisor feels as if the intended message has been delivered; however, the employee usually feels more confused and frustrated and does not recognize a need to correct his or her behavior. This form of counseling might be called, "Come in here, I need to growl at you."

The second type of mistake is one in which the supervisor spells out in great detail the employee's transgressions in a counseling document. The supervisor then presents this document, usually without much comment, for the employee to read, make written comments, and sign. This type of counseling might be called, "I got you, now sign it." The employee feels threatened, angry, defenseless, and hopeless. Even if the employee remains with the company, he or she always knows that there is a derogatory and damaging document in his or her file that will remain there forever with no way to eliminate it. The damage has been done to both parties and their relationship always will be strained.

\section{Grace and Forgiveness}

Grace, in a religious concept, refers to an unmerited favor or forgiveness. It is a common denominator in virtually all religions. The central figure of the religion can forgive and wave away all transgressions. Unfortunately, most organizations have not incorporated grace and forgiveness into their cultures. After behavior is documented as unacceptable, it must remain part of the employee's record to be used as a discriminator for salary increases, promotions, and other benefits in the future. It also must remain part of the employee's permanent record for legal reasons, providing proof that the supervisor made an attempt to rehabilitate the employee.

It is not surprising that employees react to counseling with denial, anger, threats, tears, and many other means to try to minimize the damage. In the absence of any possibility of understanding, mercy, or forgiveness, what does the employee have to lose? As long as he or she can continue to make the supervisor the one who has the problem, the employee can partially survive in the job. At the very least, the employee can hope to minimize the situation until he or she can decide how to proceed. 


\section{Transition Patterns in Counseling}

There are definable counseling transition phases that are specific to problem performance and behavior. The initial phase occurs when the counselor states the specific facts related to the employee's behavior or performance.

- Begin the counseling with the negative issues that require attention-save the positive comments for a later point in the discussion.

- Go straight to the facts and be firm and direct.

- Make the facts as clean as possible and do not rely on superficial material gathered from others.

- Do not pull out historical files, especially from previous supervisors. Completely avoid the tendency to save up faults and spring them at once.

- Before scheduling the counseling session, carefully review those procedures, policies, and practices the employee has breached. If the policies and practices have been loosely and inconsistently enforced, recognize and admit that fact at the beginning of the session. Emphasizing policy may not be well served by cracking down and making an example of one person.

The second transition phase begins with the employee's initial reaction.

- Expect a full range of behaviors and emotions.

- Above all, the supervisor must detach himself or herself for the first several minutes and allow the emotional storm to run its course - think about anything else while the employee exhausts denial, blame, and anger.

- Expect verbal attacks as a normal part of the process and do not take them personally. Allow the attacks to pass by without comment.

- Remember, without a culture of grace and forgiveness, the employee simply is trying to mitigate any damage. If the supervisor jumps in or gets pulled in at this point, he or she will not be able to proceed to the subsequent transition phases.

The employee initially may have a lack of insight into the issue being discussed. He or she may ask a barrage of questions in an attempt to define the damaging evidence. Unless the company has made it part of the culture, the employee rarely will invoke the Asoh defense (ie, willingly admit mistakes and failures) (Table 1). Proceed with extreme caution when answering these questions. Avoid naming sources of information unless doing so will establish the facts. Use excessive discretion in this instance. These sources of information

\section{TABLE 1 The ASOH Defense ${ }^{1}$}

In 1968, a Japanese airline pilot landed a transcontinental jet two and one-half miles short of the runway off the shores of San Francisco. Fortunately, no one was injured and the plane was salvaged, repaired, and returned to full service. A massive investigation took place to determine who was at fault for this near catastrophe. During months of investigation, ground crew members, passengers, and mechanics testified on both sides of the Pacific Ocean. At the end of the investigation, a hearing was scheduled to sift through all the details to determine the cause and responsibility for this mishap. The pilot, Captain Asoh, was called as the first witness during the hearing. At the hearing, when asked for his testimony regarding the cause for landing the aircraft short of the runway in the water, Asoh responded that he simply made a mistake and misjudged his location in the fog. He clearly admitted that he was the sole person responsible for the event. The hearing that was to have taken more than six months was concluded in minutes.

Japanese culture provides a mechanism for restoring harmony that is virtually unknown in the American culture. In Japan, when a mistake is made, individuals freely discuss and admit mistakes with coworkers, ask for forgiveness, and harmony is restored instantly. It is considered poor manners ever to bring it up again. In the American culture, it is assumed a person is innocent until proven guilty; therefore, an individual culturally is encouraged not to admit guilt, rather to wait until the evidence proves it. This is a costly and cumbersome process.

1. Harvey, JB. The Abilene Paradox and Other Meditations on Management. Lexington, $M A$ : Lexington Books; 1988. 


\section{The employee's initial emotional}

\section{storm usually will be short-lived if}

it is not fueled by premature

\section{comments from the supervisor.}

usually are other employees; future working relationships with them are important.

The employee's initial emotional storm usually will be short-lived if it is not fueled by premature comments from the supervisor. Answer questions in one or two sentences. Allow the employee to vent fully before reengaging. It will be obvious when he or she has calmed down and is ready to move forward with the discussion. This phase is indispensable in a culture that is not accustomed to restoring harmony by providing forgiveness as an avenue for rectifying mistakes.

The third phase involves the employee's search to understand his or her own behavior. This often is a slower process.

- Expect to hear additional defensive posturing, rationalization, and mixed emotions.

- Allow the employee to work through their emotions; it still is his or her problem, not the supervisor's. It may take one or two days for him or her to gain sufficient insight to decide on an alternative behavioral plan. Documentation and insight comprise the fourth phase.

- In keeping with the notion that the employee is the one who has the problem, I recommend allowing the employee to complete his or her own counseling record.

- Have notes to initiate the counseling, but do not formally write out a counseling record for the employee to sign, as is the customary practice.

- As an alternative, allow the employee to answer five questions in writing (Table 2). Give the employee a facts, plan, and forgiveness form with the stipulation that it be completed and returned in their own handwriting within 24 hours.

- If the institution requires the use of a company form, allow the employee to answer the questions in the appropriate locations on the company form. In any case, the employee is the person who must complete the counseling document.

The fifth phase is resolution and forgiveness.

- When the employee completes the facts, plan, and forgiveness form to the mutual satisfaction of the employee and supervisor, both parties should sign and date the agreement.

- The time lapse between the initial discussion and the document signing should not be long-at most, it should be completed in less than three days.

- In a small number of cases, the employee will refuse to gain the insight or to trust enough to reach this degree of resolution. With these employees the supervisor must document the counseling and further manage the crisis.

- In all other cases, the employee will respond with an actual and permanent change of behavior and a stronger commitment to the department and the organization.

The final, and most important phase, is to set a date and time when the counseling document will be destroyed.

- Give the employee sufficient time to work through the problem and live up to his or her commitment.

- After two, three, or six months, if there have been no further problems, plan on a specific date to destroy the employee's selfcounseling document.

- Set the date to bring the employee back to your office and conduct a ceremonial destruction of the document. Reassure the employee that there are no copies and that the matter is completely forgotten. He or she has been forgiven.

I realize that this practice is a dramatic change in the way counseling records are maintained. The good working relationship between the supervisor and the employee is the issue. It also is one of trust and commitment. For this to be achieved, absolute forgiveness must be part 


\section{TABLE 2 \\ Questions for a Facts, Plan, and Forgiveness Form}

\section{Question one: What behaviors on your part initiated this counseling?}

This allows the employee to state in their own words the nature of the issue. Be patient and firm. The employee may use the opportunity for additional emotional venting. Rarely do employees complete this initial question the first or second time to the supervisor's satisfaction. This is to be expected; remember, counseling is an exchange of ideas and opinions to reach a mutual plan. The supervisor will feel vulnerable at this point. Remain focused and resolute in allowing the employee to gain the required insight. The extra day or two it takes will be fully rewarded with an employee who understands the issues and is more willing to rejoin the team.

\section{Question two: What effect does your behavior have on the workplace and on your fellow workers?}

This question gives the employee the opportunity to reflect and document in their own words the difficulties their behavior has on the other members of the organization. Again, the first draft may not contain sufficient information. If this is the case, calmly emphasize that the employee must readdress the questions and issues on a new form and return it the morning of the next working day. Simply explain that the comments the employee made do not sufficiently address the magnitude of the issue. Causing the employee to view his or her behavior from a new perspective provides a success barometer for both the employee and the supervisor.

\section{Question three: Are there any unusual or extenuating circumstances that can explain your behavior?}

Employees often are reluctant to share private information or circumstances that may influence their poor performance or behavior. This may range from financial difficulties; marital, family, or relationship issues; untreated depression; or no reason at all. In any case, it gives the employee a chance to share outside causes that may affect or compound the original problem. In most instances, the employee will state there are no extenuating circumstances; however, if there are additional issues, be alert to the nature of the statements. Be prepared to guide the employee to seek further professional assistance, if necessary. Also be alert for comments that illustrate organizational system problems, those with the potential to turn into sentinel events.

\section{Question four: What do you intend to do to alter this behavior or to prevent this from happening in the future?}

This question guides the employee into discovering a mutually satisfactory resolution plan. This enables him or her to state, in his or her own words, what he or she is willing to do to succeed in the organization and to alter behavior. This also allows the employee to have a sense of control over his or her own employment destiny. This frequently is the wake-up call the employee has been waiting for to cause him or her to squarely face long-standing personal and work-related issues.

\section{Question five: By what date and time do you intend to accomplish this change?}

This question locks the employee into committing to restore the harmony between the damaged working relationships. The entire process of the employee completing his or her own counseling form helps him or her to maintain his or her self-image, restores his or her dignity as a respectable employee, and allows him or her to view all the issues from a sound perspective.

of the process, which means setting an appropriate, agreed-upon time between counseling and destruction of the document. During my own 15 years of experience with this technique, I never have had to counsel an employee a second time for the same issue, and only rarely for any other issue. Often, if there was another kind of issue, the employee would ask for the form. Talking about this technique with an HR professional at any organization is a good idea. Let them know that you would like to use it, and get their thoughts and input into the process. 


\section{Bringing Forgiveness into the Culture}

The act of counseling an employee for poor performance or unsuitable behavior can be unpleasant for everyone involved. By avoiding the task, department members suffer the consequences in a variety of ways. The concept of forgiveness is counterintuitive in American organizational culture; however, when the true ownership of a problem is recognized and the responsibility placed accordingly, good results are possible. The intended result of reaching a deliberate, nonpunitive, nonthreatening plan of action rarely happens in the absence of a mechanism that allows the employee to adjust course with dignity, respect, and future opportunities. By introducing the concept of harmony restoration and forgiveness, we can learn new methods for controlling expensive personnel costs and demonstrate further excellence in surgical services leadership. - nIOHN -

\section{REFERENCE}

1. Dana D. Managing Differences: How to Build Better Relationships at Work and Home. Prairie Village, KS: MTI Pub; 1999:13-21.

\section{George F. Nussbaum, $\mathrm{PhD}, \mathrm{RN}, \mathrm{CNOR}$,} was a doctoral candidate in organizational leadership at the University of Oklahoma, Norman, when this article was first published. He currently is a senior clinical planner, Health Facility Planning Agency, Falls Church, VA, and an assistant professor, Perioperative Masters Program, Graduate School of Nursing, Uniformed Services University, Bethesda, MD.

\section{Breast Cancer Guidelines Now Available in Spanish}

\section{A partnership between the Pan American Health Organization (PAHO) and the Breast Health Global} Initiative (BHGI) has resulted in availability of the Guidelines for International Breast Health and Cancer Control in Spanish, according to an August 3, 2007, news release from MediLexicon International Ltd, Cancun, Mexico. The guidelines on breast cancer detection, care, and management, which were updated and published in English in 2006, are intended to help policy makers and health care providers in lowand middle-income countries improve patient outcomes by providing evidence-based, economically feasible, and culturally appropriate practices.

Breast cancer is the most common cause of cancer-related deaths among women worldwide and is newly diagnosed in more than one million women each year. Women in low- and middleincome countries often are not diagnosed until their cancer is at an advanced stage when treatment is more expensive and less successful, resulting in higher mortality rates.

The guidelines address several breast cancer issues, including

- early detection and access to care,

- diagnosis and pathology,

- treatment and resource allocation, and

- health care systems and public policy.
Many lower-income countries face resource constraints that limit their ability to provide advanced treatments for breast cancer patients. The guidelines recommend a tiered system of resource allocation, depending on the availability of resources. For example, in countries that have only very basic health systems, the guidelines recommend educating women about performing breast self-examinations to detect lumps. In countries that have more resources available, the guidelines recommend performing targeted outreach and presenting education programs on clinical breast examinations to at-risk women, followed by ultrasound or mammography to confirm the presence of any suspected lumps.

Translation of the guidelines into the world's major languages is a goal of BHGI, and the availability of the Spanish translation will help reach ministries of health, health care providers, and policy makers in Spanish-speaking countries. The Spanish guidelines can be downloaded from the PAHO web

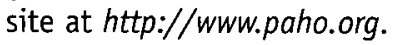

Newly available guidelines promise better results in breast cancer care [news release]. Cancun, Mexico: Medilexicon International Ltd; August 3, 2007. http:// www. medilexicon.com/medicalnews.php?newsid $=78602$. Accessed August 3, 2007. 
Copyright of AORN Journal is the property of Elsevier Science and its content may not be copied or emailed to multiple sites or posted to a listserv without the copyright holder's express written permission. However, users may print, download, or email articles for individual use. 